\title{
Macroeconomic policies and increasing social-health inequality in Iran
}

\author{
Rouhollah Zabolii ${ }^{1, *}$, Seyed Hesam Seyedin ${ }^{2}$, Zainab Malmoon ${ }^{2}$
}

Abstract

Background: Health is a complex phenomenon that can be studied from different approaches. Despite a growing research in the areas of Social Determinants of Health (SDH) and health equity, effects of macroeconomic policies on the social aspect of health are unknown in developing countries. This study aimed to determine the effect of macroeconomic policies on increasing of the social-health inequality in Iran.

Methods: This study was a mixed method research. The study population consisted of experts dealing with social determinants of health. A purposive, stratified and non-random sampling method was used. Semi-structured interviews were conducted to collect the data along with a multiple attribute decision-making method for the quantitative phase of the research in which the Technique for Order Preference by Similarity to Ideal Solution (TOPSIS) was employed for prioritization. The NVivo and MATLAB softwares were used for data analysis.

Results: Seven main themes for the effect of macroeconomic policies on increasing the social-health inequality were identified. The result of TOPSIS approved that the inflation and economic instability exert the greatest impact on social-health inequality, with an index of 0.710 and the government policy in paying the subsidies with a 0.291 index has the lowest impact on social-health inequality in the country.

Discussion: It is required to invest on the social determinants of health as a priority to reduce health inequality. Also, evaluating the extent to which the future macroeconomic policies impact the health of population is necessary. Keywords: Macroeconomic Policies, Social Determinants of Health (SDH), Inequality, Technique for Order Preference by Similarity to Ideal Solution (TOPSIS), Iran

Copyright: @ 2014 by Kerman University of Medical Sciences

Citation: Zaboli R, Seyedin SH, Malmoon Z. Macroeconomic policies and increasing social-health inequality in Iran. Int J Health Policy Manag 2014; 3: 129-134. doi: 10.15171/ijhpm.2014.70
Article History:

Received: 26 April 2014

Accepted: 19 July 2014

ePublished: 16 August 2014

*Correspondence to:

Rouhollah Zaboli

Email: rouhollah.zaboli@gmail.com

\section{Introduction}

During the past two decades, the public health attention has shifted toward the Social Determinants of Health (SDH). The World Health Organization's Commission of Social Determinants of Health (CSDH) has defined SDH as the conditions in which people are born, grow, live and work (1). The term SDH includes factors which can influence healthrelated behaviors. Socio-economic factors such as income, wealth, and education fundamentally affect health outcomes (2). Also, social infrastructures and socio-economic policies are the major determinants of health (3).

Despite a dramatic growth of research in SDH and health equity and great interest of governments and policy-makers to promote equity in healthcare, there is little evidence that healthy public policies are being adopted and implemented (4-7). From the early 1990 s to 2000 , SDH was considered as the main concern of countries, but evidence shows that the social measures taken by these countries, particularly developing countries, to decrease the inequality and promote health justice were unsuccessful (8-11).

Health inequality means inappropriate system functioning which result in inequality in social status and living conditions. CSDH was founded in 2003 to study health justice. The report of CSDH in 2008 encouraged action against health inequalities and fills the gap between socioeconomic and political factors through research on SDH.
The report proposed that inequities in power, money, and resources are responsible for the majority of the inequalities in health within and between countries (11-14). A toxic combination of poor policies and programs, unfair economic arrangements, and bad governance lead to inequalities in the conditions of daily life: the circumstances in which people are born, grow, live, work, and die (15).

Despite the improvement in health status during the past 30 years, health inequalities have caused various problems in different countries (16-18). Low- and middle-income countries face many challenges to achieve the Millennium Development Goals (MDGs). Developing countries should undertake appropriate efforts to promote maternal education, improve access to clean water and safe sanitation and better living circumstance. In developing countries, macroeconomic policies have a great influence on reducing health disparities (19-24), but there is little evidence about impact of macroeconomic policies on SDH $(19,25,26)$.

One of the main challenges of healthcare systems of Iran is health inequality. Zaboli and colleagues reviewed and prioritized SDH in Iran. They believe, socio-economic status, living facilities such as housing, and social integrity had the greatest effect on decreasing health inequality in Iran (27). Addressing SDH requires an understanding of the impact of macroeconomic policies and social policies on the health. Evidence-based policies must be relevant and integrated 
into health systems to function efficiently (28-31). Based on the conceptual framework of social determinants of health inequality, this research aimed to determine the effect of macroeconomic policies on the social-health inequality in Iran based on expert opinion and identify the drivers of SDH in Iran.

\section{Materials and methods}

This study is a mixed method research which was conducted in two phases as presented in below:

\section{Qualitative phase}

The aim of qualitative phase of this study is to determine the main themes of macroeconomic policies on SDH. In this study, experts in SDH were the study population. Purposive non-random stratified sampling was used. We divided experts into three strata including governmental, academic and independent experts, and purposeful sampling were used based on the inclusion criteria. The aim was to include individuals from a variety of backgrounds.

Experts in the areas of health management and policy, clinical, social science and other spatiality were identified and via recommendations from other recruited participants as well as individuals at SDH commission of ministry of health. Experts were defined as individuals whose past or present field contains the subject under study i.e. health policy, epidemiology, and/or clinician. Inclusion criteria followed recommendations which include evidence of expertise, understanding of the problem area, reputation, availability, and willingness to participate.

Experts were invited to take part in the research via walkthrough and personal visit that explained the aim, methods, and use of study data. We also used semi-structured interviews to collect qualitative data. The interview guide included a number of main questions regarding the SDH. The conceptual framework of study was based on the CSDH model in Figure 1. A pilot interview was conducted. Interviews were continued to reach the data saturation. The participants in this study were 24 experts. Data were collected during December 2012 and April 2013. The majority of participants were based in Tehran.

The interviews were transcribed and the transcriptions were sent to the interviewees for confirmation. Framework analysis technique was used using Nvivo software (QSR International, Australia) for the analysis. The main themes and constructs were extracted in the qualitative phase and in the quantitative phase they were prioritized.

\section{Quantitative phase}

The quantitative phase of this study was aimed to prioritize and determine factors with the greatest impact on the macroeconomic policies which result in social-health inequality in Iran.

There are various decision-making methods. A Multiple Attribute Decision-Making (MADM) approach was used to obtain feedback from the experts at the study because there are useful and simple methods to deal with decision-making problems. This methodology builds on the frequently-used MADM techniques of Technique for Order Preference by Similarity to Ideal Solution (TOPSIS).

TOPSIS methodology has a simple process and easy to use and programmable but it overcomes some typical limitations that exist in relying on these deterministic techniques. It is difficult to weight attributes and keep consistency of judgment, especially with additional attributes. TOPSIS is one of the compensatory classic methods in MADM for prioritization based on similarity to ideal solution. The Simple Additive Weighting (SAW) method was exploited to identify the weights of each factor (33-35). The experts could use the following nine-points for expressing the intensity of the preference for one criterion versus another:

$1=$ Equal importance or preference

$3=$ Moderate importance or preference of one over another $5=$ Strong or essential importance or preference

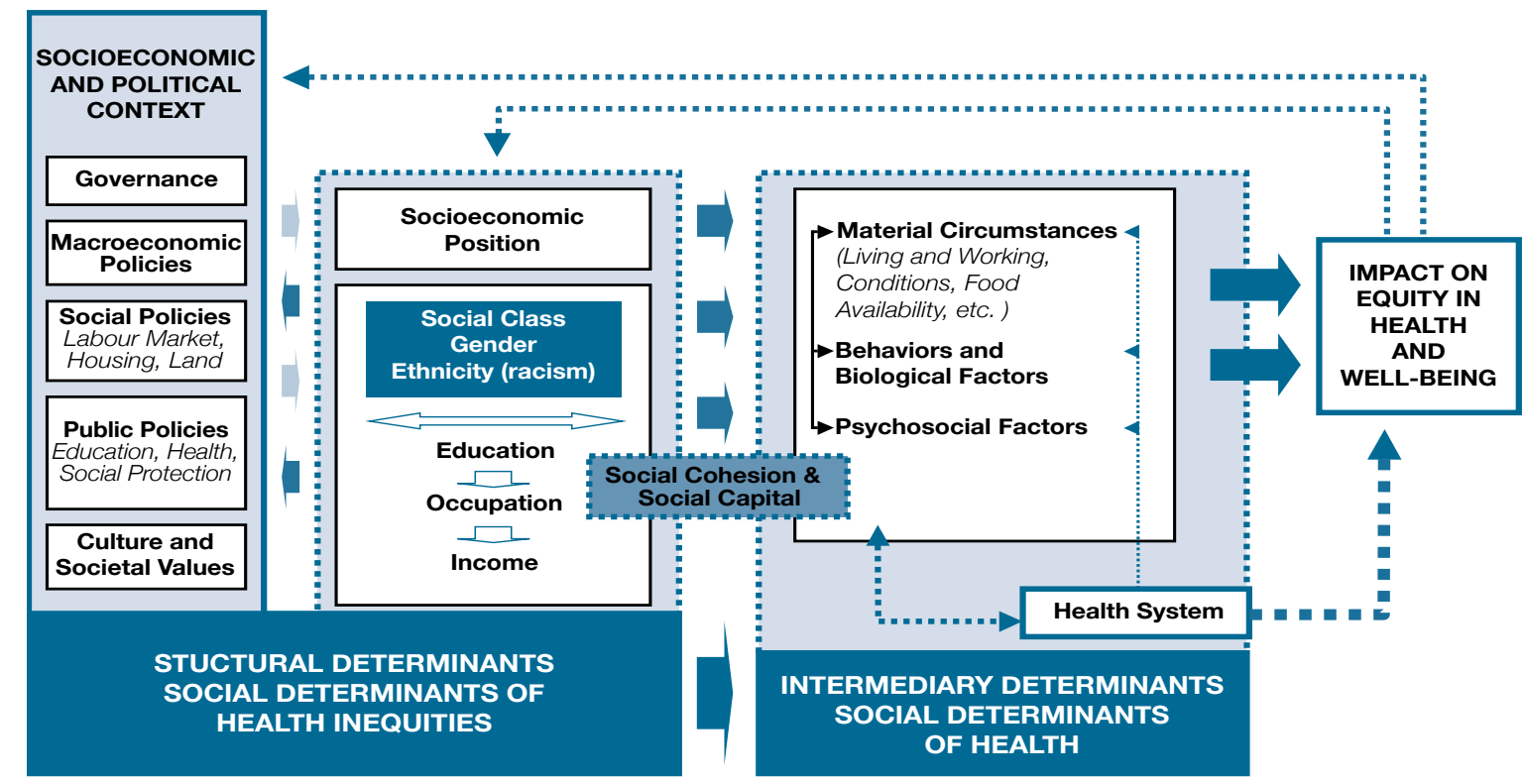

Figure 1. Final form of the CSDH conceptual framework (Reprinted with permission from WHO (32) (p. 7) 
$7=$ Very strong or demonstrated importance or preference 9= Extreme importance or preference

The TOPSIS technique is consist of the following steps:

1. Compute the normalized decision matrix. The normalized value rij is calculated as:

$r_{i j}=\frac{f_{i j}}{\sqrt{\sum_{j}^{J} f^{2}{ }_{i j}}} \quad \mathrm{j}=1, \ldots, \mathrm{J} \quad \mathrm{i}=1, \ldots, \mathrm{n}$

2. Calculate the weighted normalized decision matrix. The weighted normalized value $\mathrm{v}_{\mathrm{ij}}$ is calculated as:

$\mathrm{V}_{\mathrm{ij}}=\mathrm{w}_{\mathrm{i}} \mathrm{r}_{\mathrm{ij}} \quad \mathrm{j}=1, \ldots, \mathrm{J} \quad \mathrm{i}=1, \ldots, \mathrm{n}$

Where $\mathrm{w}_{\mathrm{i}}$ is the weight of the $i$ attribute or criterion, and $\sum_{i=1}^{n} w_{i}=1$

3. Determine the ideal and negative-ideal solution.

$$
\begin{aligned}
& A^{+}=\left\{V_{i}^{+}, \ldots V_{n}^{+}\right\}=\left\{\left(\max V_{i j} \mid i I^{\prime}\right),\left(\min V_{i j} \mid i I^{\prime \prime}\right)\right\} \\
& A^{-}=\left\{V_{i}^{-}, \ldots V_{n}^{-}\right\}=\left\{\left(\min V_{i j} \mid i I^{\prime}\right),\left(\max V_{i j} \mid i I^{\prime \prime}\right)\right\}
\end{aligned}
$$

Where $I^{\prime}$ is associated with advantage criteria and $I^{\prime \prime}$ is associated with cost criteria.

4. Calculate the separation measures, using the $n$-dimensional Euclidean distance. The separation of each alternative from the ideal solution is given as:

$$
\left.D_{j}^{+}=\sqrt{\sum_{i=1}^{n}\left(v_{i j}\right.}-v_{i}^{+}\right)^{2} \quad \mathrm{j}=1, \ldots, \mathrm{J}
$$

Similarly, the separation from the negative-ideal solution is given as:

$\left.D_{j}^{-}=\sqrt{\sum_{i=1}^{n}\left(v_{i j}\right.}-v_{i}^{-}\right)^{2} \quad \mathrm{j}=1, \ldots, \mathrm{J}$

5. Calculate the relative closeness to the ideal solution. The relative closeness of the alternative $j$ with respect to $A^{*}$ is defined as:

$$
C_{j}^{+}=\frac{D_{j}^{-}}{D_{j}^{+}+D_{j}^{-}} \quad \mathrm{j}=1, \ldots, \mathrm{J}
$$

6. Rank the preference order based on TOPSIS index. Its use of Euclidean distance does not consider the correlation of attributes; the index range does from 0 to 1 . The whole process was performed by MATLAB software MATLAB (MathWorks Inc, Natick, MA).
Results

Twenty-four experts, 14 male and 14 female, in the area of health management and policy, clinical, social science, and others spatiality were chosen. Their average age was $49.881 \pm$ 14.263 years, and average years engaged in the work was 24.616 \pm 11.542 years. The expert response rate was $100 \%$ (Table 1 ). Based on the qualitative results, macroeconomic policies have an impact on health and health inequalities in the country. All participants believe that macroeconomic factors affect social health inequalities in Iran.

"One of the things that have a great impact on the health is the general policies debate in the country including setting the tariffs, share of private sector in the financing and delivery of health services and stewardship".

Experts believed that the general economy instability have a big impact on social health inequalities.

"Economic uncertainty and high inflation impact on health inequalities and social determinants of health".

Some experts highlighted the fact that the macroeconomics policies such as subsides are important in rising inequality

"Macroeconomic policies, such as subsidies have made major problems in health financing".

There were some discussions regarding private sector policies on health inequalities. It was reported by the majority of the interviewees that expanding the private sector role in health services delivery will have a devastating impact on the concept of justice especially on poor and low-income population.

Seven themes and fifteen subthemes of macroeconomic policies were identified in which affect the social-health inequality in Iran (Table 2). The themes are Inflation and economic instability, public and private sectors policies, overall economy situation, health policy, out-off pocket, policies context and the subsidies.

Based on experts' knowledge, we prioritized these factors as follows: Inflation and economic instability has the greatest impact on social-health inequality, with a 0.710 as a TOPSIS Index and the subsidies with a 0.291 as a TOPSIS index has the lowest impact on social-health inequality in the country (Table 3).

\section{Discussion}

Despite major advances in medicine and public health during the past few decades, there are disparities in health and healthcare inequities. Evidences show in order to decrease health inequality, macroeconomic policies in all of the countries must be appropriately considered. Policymakers should attempt to reduce health inequality by paying attention to SDH. Current approaches to SDH generally focus

\begin{tabular}{|c|c|c|c|c|c|c|c|c|c|c|c|}
\hline \multirow{2}{*}{ Variable } & \multicolumn{2}{|c|}{ Gender } & \multicolumn{4}{|c|}{ Subject Area Studied } & \multicolumn{2}{|c|}{ Work Experience } & \multicolumn{3}{|c|}{ Affiliation } \\
\hline & $\begin{array}{l}\text { Male } \\
\mathbf{n}(\%)\end{array}$ & $\begin{array}{c}\text { Female } \\
\mathrm{n}(\%)\end{array}$ & $\begin{array}{l}\text { HMP } \\
\mathrm{n}(\%)\end{array}$ & $\begin{array}{c}C \\
n(\%)\end{array}$ & $\begin{array}{c}\text { SS } \\
\mathrm{n}(\%)\end{array}$ & $\begin{array}{c}\text { OS } \\
\mathrm{n}(\%)\end{array}$ & $\begin{array}{c}<15 \text { years } \\
n(\%)\end{array}$ & $\begin{array}{c}>15 \text { years } \\
n(\%)\end{array}$ & $\begin{array}{c}\text { Government } \\
\mathrm{n}(\%)\end{array}$ & $\begin{array}{c}\text { Academic } \\
\mathrm{n}(\%)\end{array}$ & $\begin{array}{c}\text { Independent } \\
\mathrm{n}(\%)\end{array}$ \\
\hline
\end{tabular}
on population-level and policy interventions. Public policy that seeks to achieve sustainable improvements in the SDH,

Table 1. Basic characteristics of experts

$\mathrm{HMP}=$ Health Management and Policy, $\mathrm{C}=$ Clinical, $\mathrm{SS}=$ Social Science, $\mathrm{OS}=$ Other Specialty 
Zaboli et al.

Table 2. Frame-worked-Derived Themes and Constructs

\begin{tabular}{llr}
\hline Items & Themes & Subthemes \\
\hline A1 & Public and private sectors policies & Policy-making process, trust in results, to increase market power in heath \\
A2 & Health policy & To empower the people, available programs and services related to SDH \\
A3 & Policies context & Health in all policies, market penetration, the incentive made for organizations \\
A4 & Out-off pocket & Increasing the OOP payment, weakness of social insurance \\
A5 & The subsidies & To increasing the cost/benefit ratio \\
A6 & Economic factors & General environment, trustfulness of the economy, trade rule, market to participate in well-being \\
A7 & Inflation and economic instability & To increase the price of services, catastrophic expenditures
\end{tabular}

Table 3. Prioritize the social determinants of health inequality by TOPSIS technique

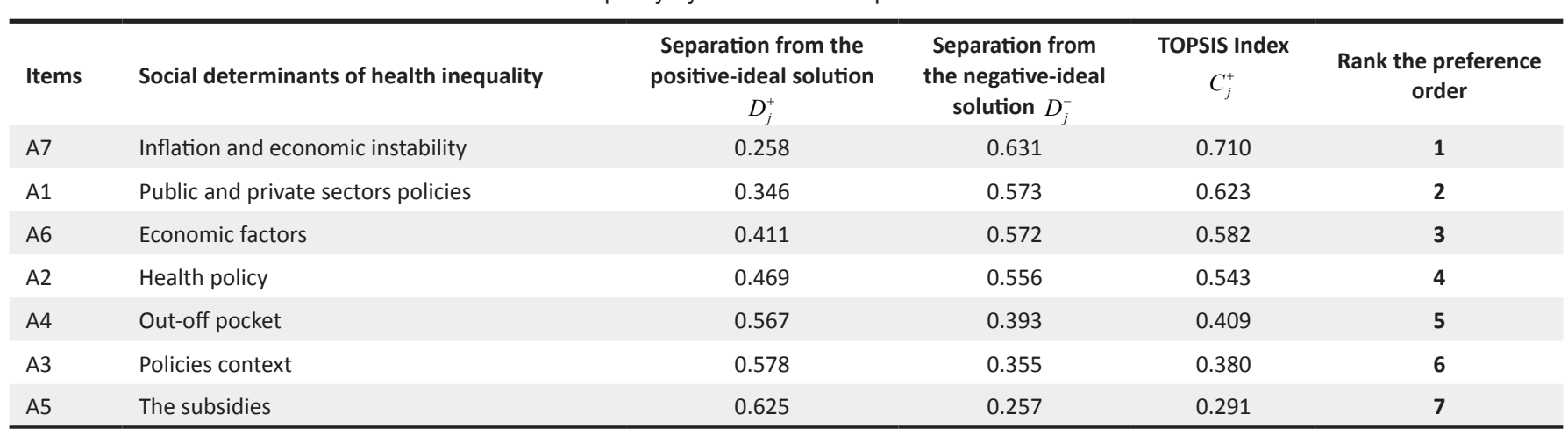

such as income, education, housing, food security, and area conditions, can create positive and sustainable health effects (36-38). Significant improvements in population health are likely when the SDH are addressed (39).

There are few studies have been conducted in the health disparities. One of the most important studies is the Urban HEART survey in Tehran city. The results of this study showed that socio-economic inequalities exist in health status in Tehran. Since the root of this avoidable inequality is in outside the health system, a holistic health policy approach which includes social and economic determinants should be adopted to redress the inequitable distribution of health (40). Results of previous studies suggested that health in all policies is an approach to health promotion. Public health, it was concluded, should be more concerned with social policies and social determinants than with health services and disease control (41). Health Impact Assessment (HIA) serves as a tool for policy-makers and planners when considering a new policy (42-46). Based on our finding, in Iran the most priorities on macroeconomics which affect health inequalities was economic instability. Results Studies of Lofters et al., Muntaner and Chung, O'Dea et al., and Parthasarathy et al. founded similar results and confirmed results of our study (47-50). Another theme which was founded in this study was private sectors policies. The private sector is making a growing contribution to healthcare in much of developing countries. There has been considerable interest in the growth of the private sectors in delivering of health services instead focusing on determinants of health (51-54).

The study suggested that the impact of macroeconomic policies on the health of people in the country must be constantly measured and before the implementation of new policies, positive or negative impacts of them must be investigated. Our results based on the experts' opinions showed that weak financial protection plans and inadequate coverage of insurances, a high level of out of pocket in health financing have negative impact on community health (55-58). Macroeconomic policies such as the subsidies have great impact on the community health in the country and the effects should be measured. The commitment to addressing underlying in often named in the phrase "tackling health inequalities". Focusing of macroeconomic policies on equal distribution of determinants such as diets, housing, workplace condition is important for thinking about policies. Action on the SDH is needed across the life course, and in wider social and economic spheres to achieve greater health equity and protect future generations $(11,59,60)$.

Socio-economic inequalities and their effects on health are one of the challenges that have recently attracted attention because improving health in afflicted societies is more difficult than helping patients in a healthy society. The majority of factors causing health inequality are distributed all over different social sectors. Therefore, it is necessary to take a multi-disciplinary approach in policy-making and to evaluate the probable effects of policies on health, particularly on the health of the most vulnerable groups of the society.

\section{Acknowledgements}

The paper is result of a research project which was funded by the Iran University of Medical Sciences. We would like to thank the experts for providing us the information.

\section{Ethical issues}

The study was approved by the ethic committee of Iran University of Medical Sciences.

Competing interests

The authors declare that they have no competing interests. 
Authors' contributions

Authors contributed to the publication of this article as follows: study concept and design (RZ); analysis and interpretation of qualitative data (RZ, SHS, and $\mathrm{ZM}$ ); statistical analysis and interpretation of quantitative data (RZ); critical revision of the manuscript (SHS).

\section{Authors' affiliations}

${ }^{1}$ Health Management Research Center, Baqiyatallah University of Medical Sciences, Tehran, Iran. ${ }^{2}$ Health Management and Economics Research center, Iran University of Medical Sciences, Tehran, Iran.

\section{References}

1. World Health Organization (WHO). Closing the Gap in a Generation: Health Equity Through Action on the Social Determinants of Health: Commission on Social Determinants of Health Final Report. Geneva: World Health Organization, Commission on Social Determinants of Health; 2008.

2. Marmot M, Friel S, Bell R, Houweling TA, Taylor S. Closing the gap in a generation: health equity through action on the social determinants of health. Lancet 2008; 372: 1661-9. doi: 10.1016/ s0140-6736(08)61690-6

3. Ahnquist J, Wamala SP, Lindstrom M. Social determinants of health--a question of social or economic capital? Interaction effects of socioeconomic factors on health outcomes. Soc Sci Med 2012; 74: 930-9. doi: 10.1016/j.socscimed.2011.11.026

4. Embrett MG, Randall GE. Social determinants of health and health equity policy research: Exploring the use, misuse, and nonuse of policy analysis theory. Soc Sci Med 2014; 108C: 14755. doi: 10.1016/j.socscimed.2014.03.004

5. Kiesler J, Vaughn LM, Kaur G. "Voicing" the social determinants of health on the backside of a horse racetrack. J Health Care Poor Underserved 2013; 24: 1074-88. doi: 10.1353/hpu.2013.0153

6. May J, Carey TA, Curry R. Social determinants of health: whose responsibility? Aust J Rural Health 2013; 21: 139-40. doi: 10.1111/ajr.12050

7. Moatti JP. [Social determinants of health inequalities: a public health research priority]. Rev Epidemiol Sante Publique 2013; 61: S123-5.

8. Abel T, Hofmann K, Schori D. Social and regional variations in health status and health behaviours among Swiss young adults. Swiss Med Wkly 2013; 143: w13901. doi: 10.4414/ smw.2013.13901

9. Alter HJ. Social Determinants of Health: From Bench to Bedside. JAMA Intern Med 2014; 174: 543-5. doi: 10.1001/ jamainternmed.2013.13302

10. Dean HD, Williams KM, Fenton KA. From theory to action: applying social determinants of health to public health practice. Public Health Rep 2013; 128: 1-4.

11. Marmot M, Pellegrini Filho A, Vega J, Solar O, Fortune K. Action on social determinants of health in the Americas. Rev Panam Salud Publica 2013; 34: 382-4.

12. Braveman $P$, Gottlieb $L$. The social determinants of health: it's time to consider the causes of the causes. Public Health Rep 2014; 129: 19-31.

13. Krumeich A, Meershoek A. Health in global context; beyond the social determinants of health? Glob Health Action 2014; 7 : 23506. doi: 10.3402/gha.v7.23506

14. Perrin VA. Social determinants of health. Health Aff (Millwood) 2013; 32: 2060. doi: 10.1377/hlthaff.2013.1102

15. Marmot M, Bell R, Goldblatt P. Action on the social determinants of health. Rev Epidemiol Sante Publique 2013; 61: S127-32. doi: 10.1016/j.respe.2013.05.014

16. Badry D, Felske AW. An examination of the social determinants of health as factors related to health, healing and prevention of foetal alcohol spectrum disorder in a northern context--the Brightening Our Home Fires Project, Northwest Territories, Canada. Int J Circumpolar Health 2013; 72: 21140. doi: 10.3402/ ijch.v72i0.21140

17. Baer TE, Gottlieb L, Sandel M. Addressing social determinants of health in the adolescent medical home. Curr Opin Pediatr 2013; 25: 447-53. doi: 10.1097/mop.0b013e32836280ae

18. Heidarnia MA, Monfared ED, Akbari ME, Yavari P, Amanpour F,
Mohseni M. Social determinants of health and 5-year survival of colorectal cancer. Asian Pac J Cancer Prev 2013; 14: 5111-6. doi: 10.7314/apjcp.2013.14.9.5111

19. Prasad A, Groot AM, Monteiro T, Murphy K, O'Campo P, Broide $E E$, et al. Linking evidence to action on social determinants of health using Urban HEART in the Americas. Rev Panam Salud Publica 2013; 34: 407-15.

20. Sanneving L, Trygg N, Saxena D, Mavalankar D, Thomsen S. Inequity in India: the case of maternal and reproductive health. Glob Health Action 2013; 6: 19145. doi: 10.3402/gha.v6i0.19145

21. Schutte S, Chastang JF, Parent-Thirion A, Vermeylen G, Niedhammer I. Social Inequalities in Psychological Well-Being: A European Comparison. Community Ment Health J 2014; forthcoming. doi: 10.1007/s10597-014-9725-8

22. Shojaei P, Karimloo M, Mohammadi F, Malek Afzali H, Forouzan AS. Position of social determinants of health in urban man-made lakes plans. Glob J Health Sci 2013; 5: 100-11. doi: 10.5539/ gjhs.v5n6100

23. Srinivasan S, Williams SD. Transitioning from health disparities to a health equity research agenda: the time is now. Public Health Rep 2014; 129: 71-6.

24. Ward PR, Mamerow L, Meyer SB. Identifying vulnerable populations using a social determinants of health framework: analysis of national survey data across six Asia-Pacific countries. PLoS One 2013; 8: e83000. doi: 10.1371/journal.pone.0083000

25. Clarke CE, Niederdeppe J, Lundell HC. Narratives and images used by public communication campaigns addressing social determinants of health and health disparities. Int J Environ Res Public Health 2012; 9: 4254-77. doi: 10.3390/ijerph9124254

26. Davies JK, Sherriff NS. Assessing public health policy approaches to level-up the gradient in health inequalities: the Gradient Evaluation Framework. Public Health 2014; 128: 24653. doi: 10.1016/j.puhe.2013.11.011

27. Zaboli R, Tourani S, Seyedin SH, Oliaie Manesh A. Prioritizing the Determinants of Social-health Inequality in Iran: A Multiple Attribute Decision Making Application. Iran Red Crescent Med J 2014; 16: e12607. doi: 10.5812/ircmj.12607

28. Freudenberg N, Tsui E. Evidence, power, and policy change in community-based participatory research. Am J Public Health 2014; 104: 11-4. doi: 10.2105/ajph.2013.301471

29. Gollust SE, Cappella JN. Understanding Public Resistance to Messages About Health Disparities. J Health Commun 2014; 19: 493-510. doi: 10.1080/10810730.2013.821561

30. Gore DM, Kothari AR. Getting to the root of the problem: health promotion strategies to address the social determinants of health. Can J Public Health 2013; 104: e52-4.

31. Hardy LJ, Bohan KD, Trotter RT, 2nd. Synthesizing evidencebased strategies and community-engaged research: a model to address social determinants of health. Public Health Rep 2013; 128: 68-76.

32. Solar OAI, World Health Organization. A conceptual framework for action on the social determinants of health. Social Determinants of Health. Discussion Paper 2 (Policy and Practice). 2010. Available from: http://www.who.int/social_determinants/corner/ SDHDP2.pdf

33. Chen CT. Extensions of the TOPSIS for group decision-making under fuzzy environment. Fuzzy Sets and Systems 2000; 114 : 1-9. doi: 10.1016/s0165-0114(97)00377-1

34. Lai YJ, Liu TY, Hwang CL. Topsis for MODM. Eur J Oper Res 1994; 76: 486-500. doi: 10.1016/0377-2217(94)90282-8

35. Shih HS, Shyur HJ, Lee ES. An extension of TOPSIS for group decision making. Mathematical and Computer Modelling 2007; 45: 801-13. doi: 10.1016/j.mcm.2006.03.023

36. Gottlieb L, Sandel M, Adler NE. Collecting and applying data on social determinants of health in health care settings. JAMA Intern Med 2013; 173: 1017-20. doi: 10.1001/jamainternmed.2013.560

37. Ingram M, Schachter KA, Sabo SJ, Reinschmidt KM, Gomez S, De Zapien JG, et al. A community health worker intervention to address the social determinants of health through policy change. J Prim Prev 2014; 35: 119-23. doi: 10.1007/s10935-013-0335-y

38. Jackson CS, Gracia JN. Addressing health and health-care 
disparities: the role of a diverse workforce and the social determinants of health. Public Health Rep 2014; 129: 57-61.

39. Kickbusch I, Williams C, Lawless A. Making the most of open windows: establishing health in all policies in South Australia. Int J Health Serv 2014; 44: 185-94. doi: 10.2190/hs.44.1.k

40. Morasae EK, Forouzan AS, Majdzadeh R, Asadi-Lari M, Noorbala AA, Hosseinpoor AR. Understanding determinants of socioeconomic inequality in mental health in Iran's capital, Tehran: a concentration index decomposition approach. Int $J$ Equity Health 2012; 11: 18. doi: 10.1186/1475-9276-11-18

41. Imani-Nasab $\mathrm{MH}$, Seyedin $\mathrm{H}$, Majdzadeh $\mathrm{R}$, Yazdizadeh $\mathrm{B}$, Salehi M. Development of Evidence-Based Health Policy Documents in Developing Countries: A Case of Iran. Glob J Health Sci 2014; 6: 27. doi: 10.5539/gjhs.v6n3p27

42. Jackson SF, Birn AE, Fawcett SB, Poland B, Schultz JA. Synergy for health equity: integrating health promotion and social determinants of health approaches in and beyond the Americas. Rev Panam Salud Publica 2013; 34: 473-80.

43. Leong $D$, Roberts $E$. Social determinants of health and the affordable care act. R I Med J (2013) 2013; 96: 20-2.

44. Suther E, Sandel M. Health impact assessments. $R /$ Med $J$ (2013) 2013; 96: 27-30.

45. Wang MP, Viswanath K, Lam TH, Wang X, Chan SS. Social determinants of health information seeking among Chinese adults in Hong Kong. PLoS One 2013; 8: e73049. doi: 10.1371/ journal.pone.0073049

46. Welch VA, Petticrew M, O'Neill J, Waters E, Armstrong R, Bhutta $Z A$, et al. Health equity: evidence synthesis and knowledge translation methods. Syst Rev 2013; 2: 43. doi: 10.1186/20464053-2-43

47. Lofters A, Slater M, Kirst M, Shankardass K, Quinonez C. How do people attribute income-related inequalities in health? A cross-sectional study in Ontario, Canada. PLoS One 2014; 9: e85286. doi: 10.1371/journal.pone.0085286

48. Muntaner $\mathrm{C}$, Chung $\mathrm{H}$. Commentary: macrosocial determinants, epidemiology, and health policy: should politics and economics be banned from social determinants of health research? J Public Health Policy 2008; 29: 299-306. doi: 10.1057/jphp.2008.23

49. O'Dea JA, Chiang $H$, Peralta LR. Socioeconomic patterns of overweight, obesity but not thinness persist from childhood to adolescence in a 6 -year longitudinal cohort of Australian schoolchildren from 2007 to 2012. BMC Public Health 2014; 14 222. doi: 10.1186/1471-2458-14-222

50. Parthasarathy P, Dailey DE, Young ME, Lam C, Pies C. Building Economic Security Today: making the health-wealth connection in Contra Costa county's maternal and child health programs. Matern Child Health J 2014; 18: 396-404. doi: 10.1007/s10995013-1309-7

51. Ritchie D, Nolan PA. Health in all policies: a start in rhode island. R I Med J (2013) 2013; 96: 31-6.

52. Tallarek nee Grimm MJ, Helgesen MK, Fosse E. Reducing social inequities in health in Norway: concerted action at state and local levels? Health Policy 2013; 113: 228-35. doi: 10.1016/j. healthpol.2013.09.019

53. Thakur J, Prinja S, Garg CC, Mendis S, Menabde N. Social and Economic Implications of Noncommunicable diseases in India. Indian J Community Med 2011; 36: S13-22. doi: 10.4103/09700218.94704

54. Urbanos R. [Health in all policies. Is the economic depression a time of opportunities? SESPAS Report 2010]. Gac Sanit 2010; 24: 7-11.

55. South J, Phillips G. Evaluating community engagement as part of the public health system. J Epidemiol Community Health 2014; 68: 692-6. doi: 10.1136/jech-2013-203742

56. Tozer AP, Belanger P, Moore K, Caudle J. Socioeconomic status of emergency department users in ontario, 2003 to 2009. CJEM 2013; 15: 1-7.

57. Vogel L. Ottawa needs to address social determinants of health, Canadians tell CMA. CMAJ 2013; 185: E599. doi: 10.1503/ cmaj.109-4566

58. Yavangi M, Sohrabi MR, Riazi S. Out of pocket payment for obstetrical complications: a cost analysis study in iran. Int J Prev Med 2013; 4: 1296-303.

59. Marmot M, Allen J, Bell R, Bloomer E, Goldblatt P. WHO European review of social determinants of health and the health divide. Lancet 2012; 380: 1011-29. doi: 10.1016/s01406736(12)61228-8

60. Priya R, Chikersal A. Developing a public health cadre in 21 st century India: addressing gaps in technical, administrative and social dimensions of public health services. Indian J Public Health 2013; 57: 219-24.

\section{Key Messages}

Implications for policy makers

- Despite the improvement in health status, health inequalities have caused various problems in different countries. Hence, focus on tackling health inequalities should be the priority of policy-makers.

- Addressing Social Determinants of Health (SDH) requires an understanding of the impact of macroeconomic policies and social policies on the health. The main causes of health disparities root in economic and social inequalities.

- Social infrastructures and socio-economic policies are the major determinants of health. Policy-makers should improve the socio-economic status of the people. Public health, it was concluded, should be more concerned with social policies and social determinants than with health services and disease control.

- From the application of the Technique for Order Preference by Similarity to Ideal Solution (TOPSIS) methodology to a real case, the approach proposed proved to an appropriate tool, which makes it possible to easily and effectively rank determinants of health.

\section{Implications for public}

Macroeconomic policies exert great impact on the community's health; hence, its effects should be measured. Focusing of macroeconomic policies on equal distribution of determinants is important for thinking about policies. An improvement of macroeconomic and social indicators in the community will lead to improvements in health indicators. 